\title{
ASSESSMENT OF STRESS ON HORSES THROUGH The SAlivary CoRTisol Concentration
}

\author{
JANZEKOVIC, M. \& PRISENK, J.
}

Abstract: The aim of this study was to determine the effect of lunging on the concentration of salivary stress hormone cortisol on the horses. The study comprised four horses ( 2 mares and 2 castrates). Lunging, which consisted by stroke, trot and canter had 30 minutes duration in total. Saliva samples of each horse were taken 4 times during the experiment in the same order, i.e. before the activity and after it. Salivary cortisol concentrations were determined in duplicates using a commercial kit for biochemical assay of cortisol (Cortisol ELISA RE52611). The effect of lunging on salivary cortisol levels was analyzed by using t-test. Average cortisol concentration before lunging amounted to $0.131 \mathrm{mg} / \mathrm{dl}$ (between 0.025 and $0.211 \mathrm{mg} / \mathrm{dL}$ ) and to 0.127 $\mathrm{mg} / \mathrm{dL}$ (between 0.035 and $0.236 \mathrm{mg} / \mathrm{dL}$ ) after the lunging. The results showed there is no statistical significant effect of lunging on salivary cortisol concentration, which indicates that lunging activity does not represent the reason for increasing the stress value on horses.

Key words: stress value, horses, assessment, cortisol
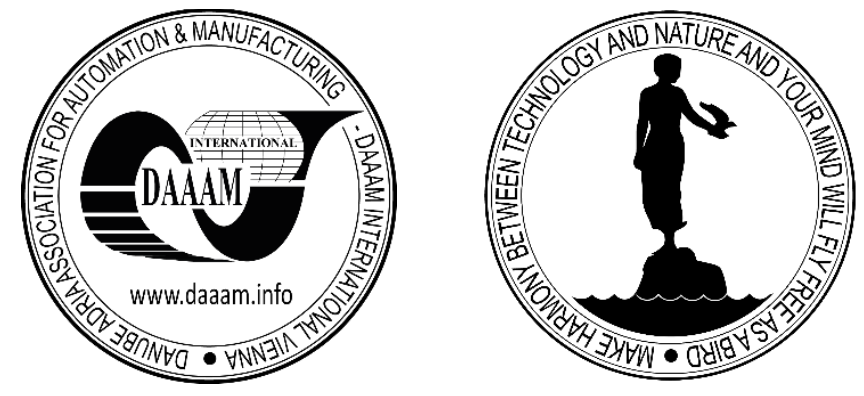

Authors' data: Assis. Prof. Dr. Sc. Janzekovic, M[arjan]*; Assis. Prof. Dr. Sc. Prisenk, J[ernej] ${ }^{*}, *$ University of Maribor, Faculty for Agriculture and Life Sciences, Pivola 11,2311 Hoce, Slovenia, majan.janzekovic@um.si,jernej.prisenk@um.si

This Publication has to be referred as: Janzekovic, M[arjan] \& Prisenk, J[ernej] (2017). Assessment of Stress on Horses through the Salivary Cortisol Concentration, Chapter 05 in DAAAM International Scientific Book 2017, pp.055-062, B. Katalinic (Ed.), Published by DAAAM International, ISBN 978-3-902734-12-9, ISSN 17269687, Vienna, Austria

DOI: $10.2507 /$ daaam.scibook.2017.05 


\section{Introduction}

In this study, we investigated the effect of lunging on the horses welfare and stress. Lunging is an ideal way to warm up the horse with effect of losing the overload energy. This is important for preparing the horse for the competition (different equestrian disciplines). Lunging starts with the walk in both directions and takes about 10 minutes. It is very important to change strokes and directions. When the horse is warm, we can continue with the trot and later with the gallop. The optimal length of the lunging is up to 30 minutes of intensive work. Cooling is in the reverse order. In the event where the horses are warmed up before the riding, lunging can be shorter with light intensive. If the lunging is high intensive, the cooling process should be longer. After the intensive part, the cooling is carried out for at least 10 minutes while walking.

It is known that various anthropological factors (such as exercise, competitions, transport, treatment, etc.) are known as stressful situations (Janzekovic et al. 2013, Stuhec 2016). As an indicator for the assessment the stress value, we used the concentration of salivary stress hormone cortisol also known as the non-invasive method. Our hypothesis was, that exercise would cause an increase in cortisol content in saliva, but it would not be recognized as extreme stressful situations.

\section{Materials and methods}

\subsection{Horses description}

Four horses ( 2 mares and 2 castrates) of the Icelandic breed at the age between 9 and 13 years have been included. The breeding carried out in open-air and open stables. Breeders organize riding camps for children throughout the year, riding courses and field trips.

Icelandic horse breed has specific characteristics, such as suitable for endurance, with strong, calm and friendly character. Furthermore these horses are not afraid, very confident, reliable, friendly and helpful, lively temperament and mastering five types of strokes (walk, stroke, center/gallop and two intermediate phases between stroke and gallop). These horses are not very demanding for care, it is best suited for open-air system breeding, it is resistant to cold and has long life with good fertility. Because of its size (such as ponies), the breed is especially popular for children.

\subsection{Sampling method}

We took samples of saliva before and after the lunging (walk, stroke, center/gallop). The time was carried out for 30 minutes at the same intense for all horses. The samples of saliva were taken 4 times from all horses in one month during springtime. For sampling we used sterile gauze (buffer, Salivette SARSTEDT, LOT 0070201). We held the buffer in one hand while in the other hand we opened the horse' mouth and inserted a buffer. The collected samples were stored in plastic labeled bags, placed in a cooling bag at $4^{\circ} \mathrm{C}$, ready for transport to a chemical laboratory at the Faculty of Agriculture and Life Sciences in Maribor (FALS), Slovenia. The samples were centrifuged for 15 minutes at $2500 \mathrm{r} / \mathrm{min}\left(\right.$ at $\left.\mathrm{T}=4^{\circ} \mathrm{C}\right)$. After centrifugation, the 
saliva was poured into plastic tubes and stored in a deep freeze at $-20^{\circ} \mathrm{C}$ until the biochemical analysis of cortisol.

\subsection{Biochemical determination of cortisol}

\subsubsection{ELISE principle}

To determine the content of cortisol in saliva, a commercial kit Cortisol ELISA (Enzyme-Linked Immune Sorbent Assay) RE52611 (manufacturer IBL Hamburg) was used. The kit is used for immunological (biochemical) analysis for the quantitative determination of free cortisol content in saliva and total cortisol content in the blood serum by antibodies in in-vitro conditions. ELISA is a biochemical method.

ELISA is one of the best validated and most routinely used immunoassay in allergy research, in allergy diagnosis in allergy-related quality control in various industries. Although as a technique it has been implemented for the last 45 years, the evolution in biochemistry allowed the development of ultrasensitive ELISA variations that are capable of measuring quantities in the scale of picograms, rendering ELISA attractive, robust, and very famous (Konstantinou 2017).

In the ELISA procedure, an unknown amount of antigen in the sample and a precise amount with an enzyme labeled antigen compete for binding sites on antibodies that are adhered on the walls. After incubation, the plate is washed up and the reaction of the contest is stopped. After the reaction with the addition of the substrate, the intensity of the developed color is inversely proportional to the amount of antigen present in the sample. The results on the samples can be determined directly using the standard calibration curve.

\subsubsection{Testing procedure}

Biochemical determination of cortisol was carried out at the FALS. Before the biochemical analysis in the laboratory, the frozen samples were warmed up to room temperature. Before the pipetting, we carefully mixed the samples with vortex mixer. The commercial kit, for the determination of cortisol, contains microscopic plates with 96 holes (dimension $12 \mathrm{~mm} \times 8 \mathrm{~mm}), 6$ standard cortisol concentrations $(0,0.3,0.6,2.0$, $6.0,15$ and $40 \mathrm{mg} / \mathrm{ml}$ ) and control solutions. We pipetted $50 \mu \mathrm{l}$ of standards, controls and samples into the appropriate microtiter plate holes. After that, we analyzed the individual samples in two repetitions. $100 \mu \mathrm{l}$ of an enzyme conjugate was added to each hole. The microtiter plate was covered with self-adhesive foil and incubated for 2 hours (at $\mathrm{T}=18-25^{\circ} \mathrm{C}$ ) on a shaker at $400-600 \mathrm{rpm}$. The washing was followed by a buffer solution (4 times of $250 \mathrm{ml}$ buffer). Then $100 \mu \mathrm{l}$ of the substrate solution was added to each hole and re-incubated for 30 minutes $\left(\right.$ at $\left.\mathrm{T}=18-25^{\circ} \mathrm{C}\right)$ at the shaker at 400-600 rpm. The reaction of the substrate was stopped by adding $100 \mu 1$ of the solution and shaking slightly. The color was changed from blue to yellow. Within 15 minutes after addition of the "stop" solution, an optical density was measured using a spectrometer at $450 \mathrm{~nm}$. 


\subsubsection{Results calculation}

On the basis of the results obtained for the standard solutions, the calibration curve was calculated (Figure 1). The absorbance values, obtained by reading the optical density of the standards, were applied to the y-axis, and the concentration of the standards to a horizontal $\mathrm{x}$-axis, where the logarithmic criterion (semi-logarithmic chart) was used. The mean value of absorbance for each sample (parallels mean value) was used. The most suitable shape of the curve was the four-parameter logistic regression. The obtained calibration curve is useful for determining the concentrations of cortisol in saliva in the range between 0.015 and $4.0 \mu \mathrm{g} / \mathrm{dl}(0.15-40 \mathrm{ng} / \mathrm{ml})$. On the basis of the measured optical density of the samples, the concentration of cortisol in the samples was determined from the curve.

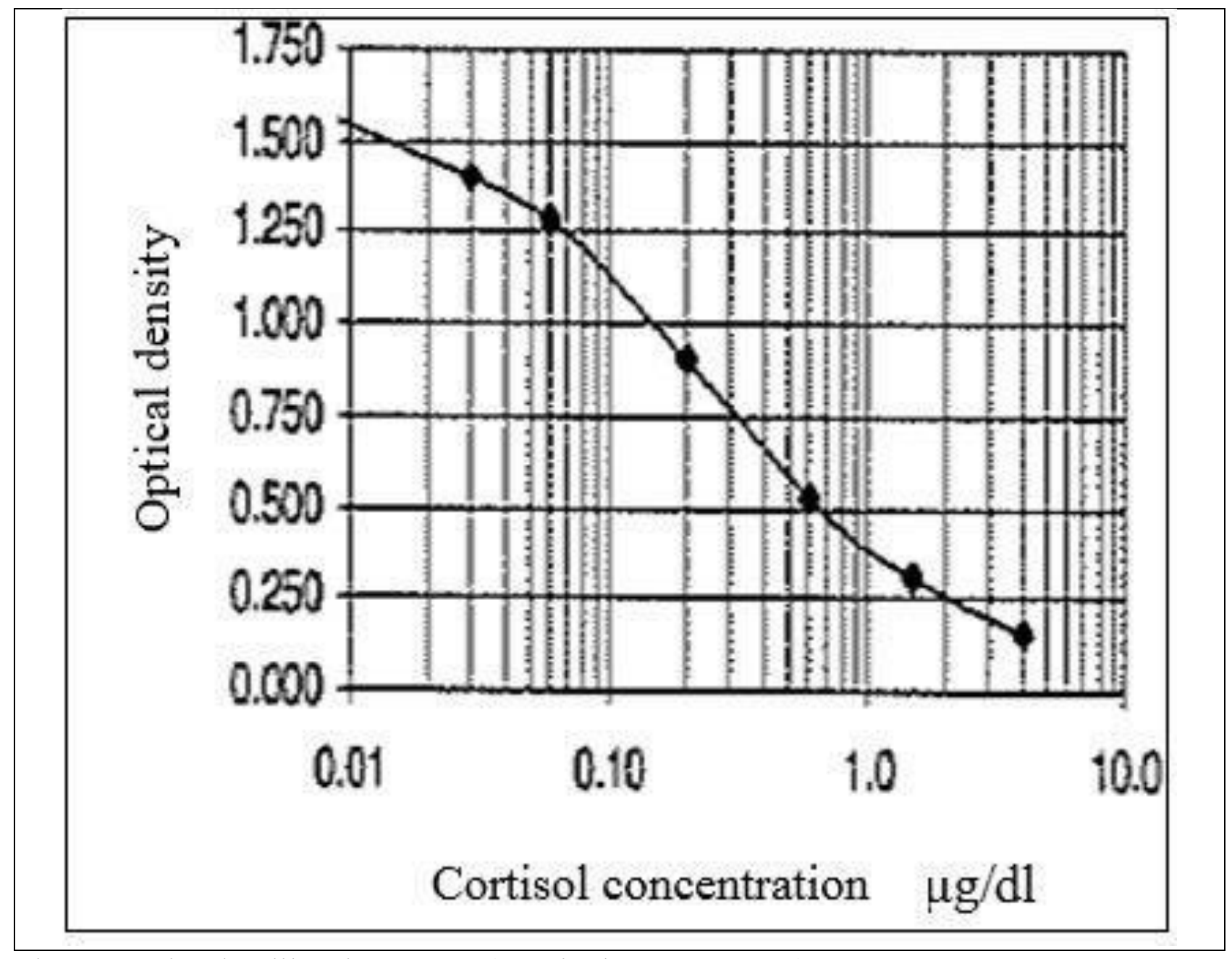

Fig. 1. Optimal calibration curve (Cortisol ELISA 2015).

\subsection{Statistical analysis}

Preparing the input data for statistical analysis was carried out by Microsoft Office Excel 2010. Later the statistical package SPSS 20.0 (2011) was used. T-test procedure and the equilibrium of the mean values for testing cortisol concentration before and after lunging were used (Analyze $\rightarrow$ Compare Means $\rightarrow$ Paired samples t-test). 


\section{Results and discussion}

\subsection{Horse characteristics}

Table 1 presents the basic characteristics of the horses used in the study. Horses Niklas and Vinur are castrats, while Atorka and Vaka are mares. Vinur was the most ively of all of them, because he is the youngest, while we did not notice any particularities in others.

\begin{tabular}{|c|c|c|c|c|}
\hline & NIKLAS & ATORKA & VAKA & VINUR \\
\hline Height $(\mathrm{cm})$ & 142 & 140 & 136 & 137 \\
\hline Weight $(\mathrm{kg})$ & 400 & 380 & 300 & 350 \\
\hline Years & 13 & 11 & 13 & 9 \\
\hline
\end{tabular}

Tab. 1. Physical characteristics of horses

Figure 2 shows the results of determination the content of cortisol value. Before the activity, the values ranged between 0.025 and $0.211 \mu \mathrm{g} / \mathrm{dl}$ (average value was $0.131 \mu \mathrm{g} / \mathrm{dl}$ ). After the activity, the values ranged between 0.035 and $0.236 \mu \mathrm{g} / \mathrm{dl}$, and average amount was $0.127 \mu \mathrm{g} / \mathrm{dl}$.

In the one of the related study Strzelec (2011) author explained that the values of cortisol concentration in saliva ranged from 0.43 to $3.45 \mathrm{nmol} / \mathrm{dm} 3$ in late evening measurements, from 0.29 to $2.43 \mathrm{nmol} / \mathrm{dm} 3$ early in the morning and from 0.28 to 8.39 $\mathrm{nmol} / \mathrm{dm} 3$ after the activity.

In the study carried out by Erber et al. (2012), the concentrations of cortisol in saliva ranged from 1.4 to $1.8 \mathrm{ng} / \mathrm{ml} 30-60$ minutes after microchipping/stamping the animal.

In the study Shanahan (2013), the concentration of cortisol in saliva ranged from 0.069 to $0.101 \mu \mathrm{g} / \mathrm{dl}$ before loading the horses on trailer, and after that it was 0.086 and $0.123 \mu \mathrm{g} / \mathrm{dl}$.

In the study which was made by Becker-Birck et al. (2013), the concentration of cortisol in saliva ranged from 0.5 to $2.2 \mathrm{ng} / \mathrm{ml}$ during the dressage, show jumping and competition. Peeters et al. (2013) reported that cortisol value in saliva was between 1.18 and $1.92 \mathrm{nmol} / 1$ for horses during the rest and the competition. 


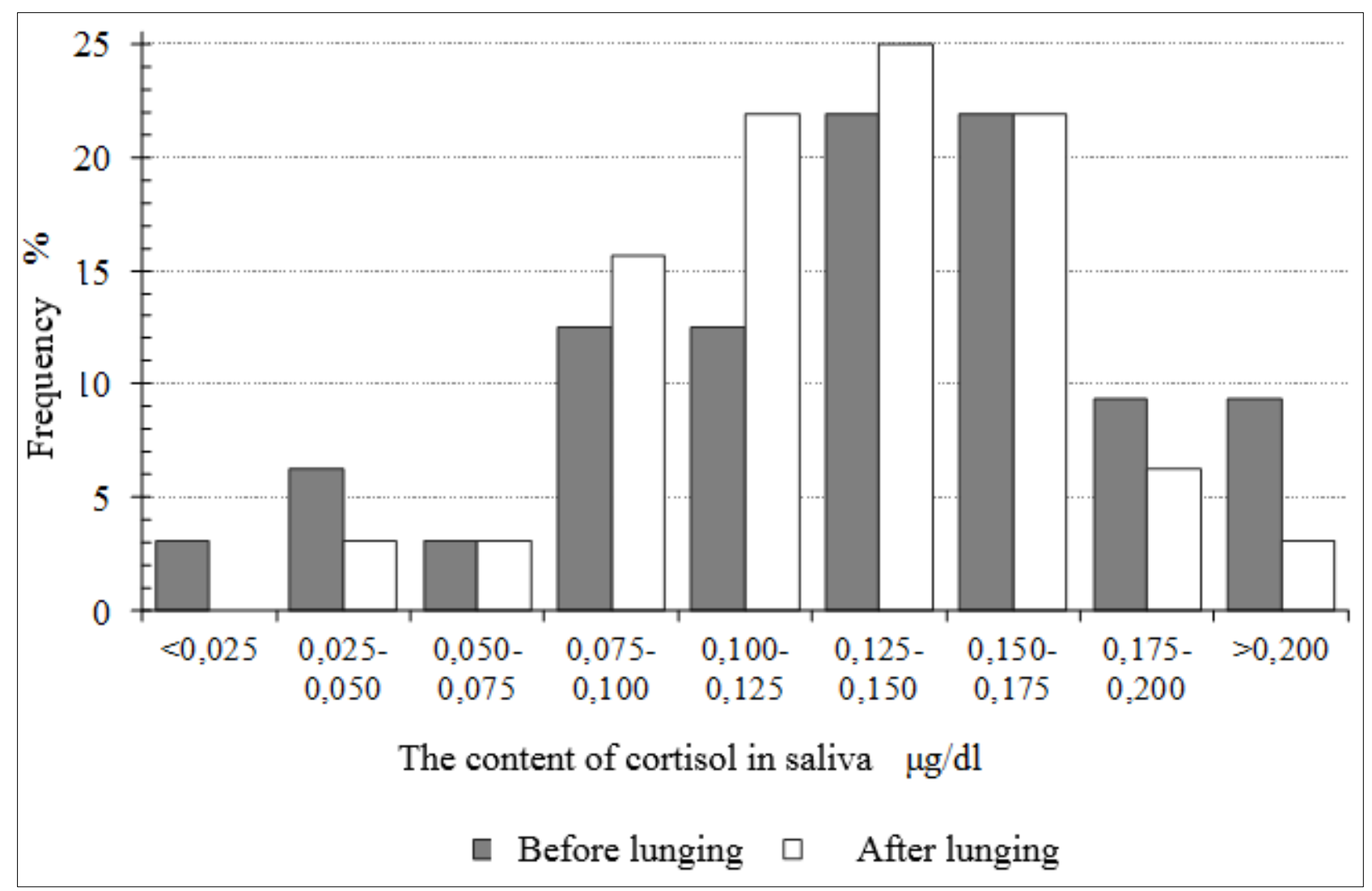

Fig. 2. The cortisol values before and after the lunging.

Figure 3 represents the comparison the content of cortisol in saliva on tested horses before and after the lunging. Results show statistical insignificant differences before and after the activity. The value after the lunging $(0.127 \mu \mathrm{g} / \mathrm{dl})$ is even slightly lower than before lunging $(0.131 \mu \mathrm{g} / \mathrm{dl})$, which was not expected according to the literature review. From the literature review can be found that the cortisol value achieve the maximum in 20-30 minutes after the starting the activity. It could also happened that maximum value can be arranged a little bit earlier or even before the starting the activity (Strzelec et al. 2011). The reasons for lower concentration of the cortisol could not be found in inappropriate sample collection method, because the duration of the exercises was at least 30 minutes. Most literature studies indicate that various sports and recreational activities in horses lead to a significant increase in the content of cortisol (Ferlazzo et al. 2012, Becker-Birch et al. 2013). These kind of activities are especially equestrian competitions, i.e. show jumping (longer and intensive activities). It is known that duration and intensity of the exercises have the influences on the content of the cortisol in saliva, while the duration has a higher impact. In our study, the exercise was quite short (30 minutes) and especially light. Strzelec et al. (2011), who tested different training modes (based on duration and intensity), found that recreation riding can lead to a slight increase in cortisol content, but differences in comparison with the control group are not typical and that go in hand to hand with our expectations. Authors Strzelec et al. (2011) concluded that the possible reasons for these results can be found in fact that short and light exercise does not cause the true stress reaction. Further, cortisol measured in saliva maybe is not an appropriate 
indicator of the actual condition. This is one of the possible explanations for our results. On the other hand, a possible reason for the results is that lunging has positive affect on horse welfare and does not represent a stressful situation. According to the Gardiner (1995), the horse with appropriate lunging approach is relaxed, active and happy. A slightly higher concentration of cortisol before the lunging can be explained by the horse's reaction after the excluding from the herd. The reason for the results can also be the horse breed - The Icelandic horse. In the scientific literature we have not found any similar research on Icelandic horses so far.

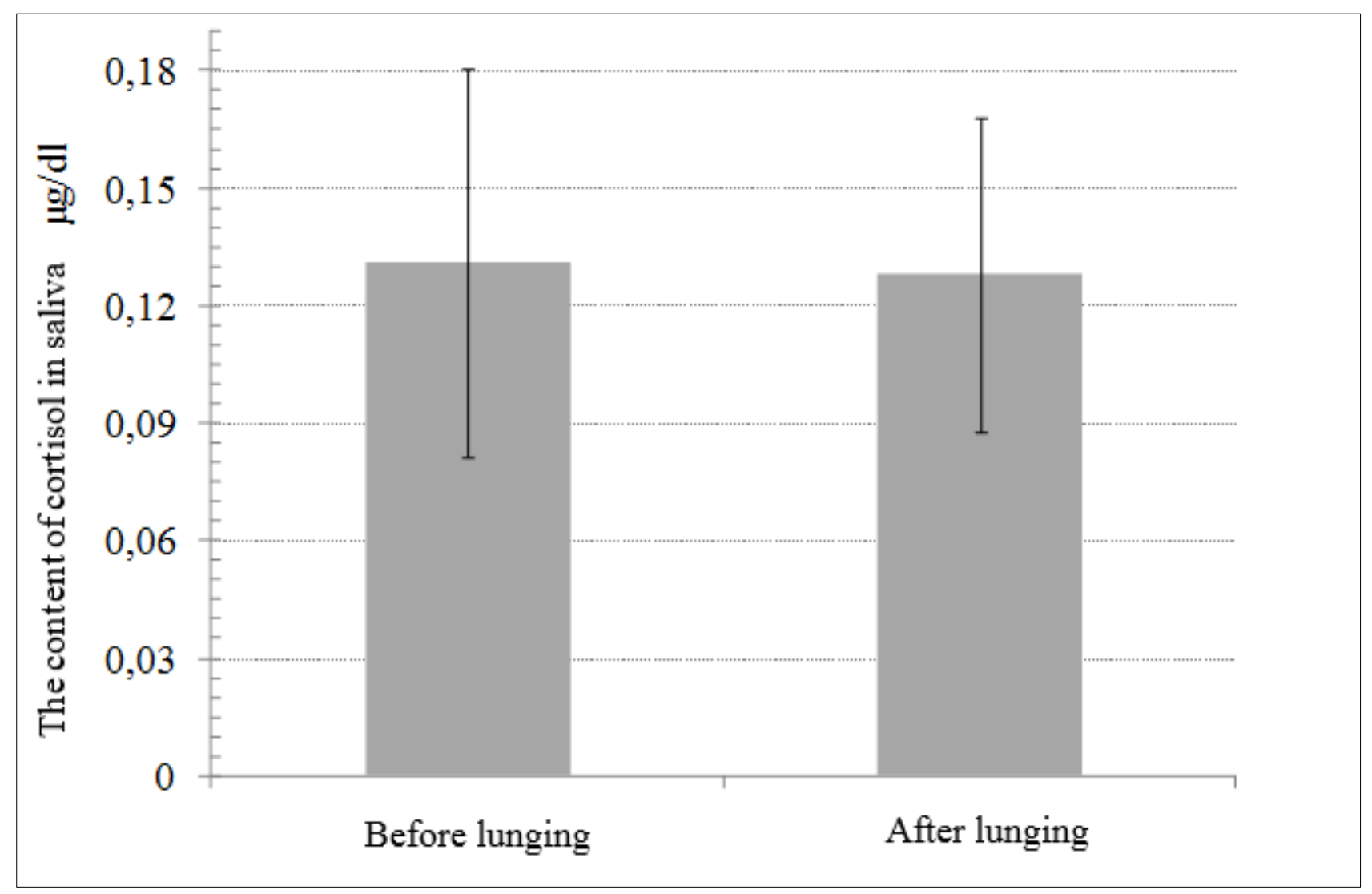

Fig. 3. Comparison of average cortisol value in saliva before and after lunging

\section{Conclusion}

This study clearly examined the influence of 30-minute lunging (light intensive activity) on the cortisol value in saliva on the Icelandic horse breed. The content value of cortisol in saliva before and after the activity was not statistically significant. Based on the results we can conclude that the exercise, which was exposed to our experimental horses is not a reason for the stress on the animals. The results indicate that lunging has a beneficial effect on the welfare of horses. On the other hand, it is possible that due to the light intensive exercise, the used method is not suitable for the evaluation of the stress condition. According to this conclusion, the adequately idea for the further research can be seen in including the others types of warm-blooded horses with high intensive exercise ability. 


\section{References}

Becker-Birck, M.; Schmidt, A.; Lasarzik, J.; Aurich Möstl, E. \& Aurich, C. (2013). Cortisol release and heart rate variability in sport horses participating in equestrian competitions. Journal of Veterinary Behavior, Vol. 2, pp. 87-94, ISSN 1558-7878 Cortisol ELISA. 2015. IBL International GmbH. Hamburg, RE 52611. Instructions for use, Version 2015-01, 10 pp. http://www.ibl-international.com (Accessed on: 26.07.2017)

Erber, R.; Wulf, M.; Becker-Birck, M.; Kaps, S.; Aurich, JE; Möstl, E. \& Aurich, C. (2012). Physiological and behavioural responses of young horses to hot iron branding and microchip implantation. Veterinary Journal, Vol.191 pp. 171-175, ISSN 10900233

Ferlazzo, A; Medica, P.; Cravana, C. \& Fazio, E. (2012). Circulating $\beta$-endorphin, adrenocorticotropin, and cortisol concentrations of horses before and after competitive show jumping with different fence heights. Journal of Equine Veterinary Science, Vol. 32, No.11, pp. 740-746, ISSN 0737-0806

Gardiner, T. (1995). Training the dressage horse, novice to medium level. London, Ward Lock, 176 p. ISBN 9780549653912

Janzekovic, M., Kraner Sumenjak, T., Sustar, V., Janzekovic, I. \& Pajtler, A. (2013). Rebuilding and installation of the sensor heart rate monitor Garmin Forerunner 305 in the hourse's saddle harness. In: DAAAM International scientific book 2013, Katalinic, B. (Ed.); Tekic, Z. (Ed.), pp. 431-440, Published by DAAAM International Vienna 2013, ISSN 1726-9687

Konstantinou, G.N. (2017). Enzyme-Linked Immunosorbent Assay (ELISA). Food Allergens. In: Methods in Molecular Biology book series MIMB, pp. 79-94, ISBN 9781-4939-6923-4

Peeters, M.; Closson, C; Beckers, J-F \& Vandenheede, M. (2013). Rider and Horse Salivary Cortisol Levels During Competition and Impact on Performance. Journal of Equine Veterinary Science, Vol. 33, No. 3, pp. 155-160, ISSN 0737-0806

Shanahan, S. (2013). Trailer Loading Stress in Horses: Behavioral and Physiological Effects of Nonaversive Training (TTEAM). Journal of Applied Animal Welfare Science, Vol. 6, No. 4, pp. 263-274, ISSN 1088-8705

SPSS 20.0 (2011). IBM SPSS Statistics 20 Core System User's Guide. https://www.csun.edu/sites/default/files/statistics20-core-system-guide-64bit.pdf (Accessed on: 26.07.2017).

Strzelec, K.; Kankofer, M. \& Pietrzak, S. (2011). Cortisol concentration in the saliva of horses subjected to different kinds of exercise. Acta Veterinaria, Vol. 80, pp. 101105, ISSN 0001-7213

Stuhec, I. (2016). Etologija domacih zivali. Univerzitetni ucbenik. I. izdaja. Univerza v Ljubljani, Biotehniska Fakulteta, Oddelek za zootehniko, Domzale, pp. 22-25, ISBN 978-961-6204-72-9. 